\title{
Representações Sociais de Doente Mental na Percepção dos Cuidadores
}

\author{
Irineide Beserra Braga ${ }^{1}$; Juliana de Freitas Vasconcelos ${ }^{2}$; Anny Caroline Costa Vieira ${ }^{3}$; \\ Thércia Lucena Grangeiro Maranhão ${ }^{4}$
}

\begin{abstract}
Resumo: As constantes reclamações com relação ao tratamento mental hospitalar, por parte de familiares de indivíduos portadores de transtornos mentais, motivaram o questionamento de como seria a representação de doente mental para estas pessoas. Objetivo: Conhecer as representações sociais de doença mental que possuem os familiares de pacientes psiquiátricos. Método: enquanto pesquisa qualitativa, aplicou-se um questionário de levantamento de conceitos, opiniões e sentimentos em 29 sujeitos, parentes de pacientes do Hospital Santa Tereza, Crato, estado do Ceará. Os dados foram submetidos à análise de conteúdo, segundo Bardin, tendo como suporte referencial teórico-metodológico a teoria moscoviciana de representação social. A análise dos dados possibilitou a estruturação das representações sociais acerca de doença mental, elaboradas pelos familiares dos internos, em três categorias. Resultados: com relação a Concepção que os sujeitos têm de Doença mental, sobressaíram-se duas subcategorias: Moral (desvio em relação ao comportamento normal) e Mística (algo difícil de explicar); a Concepção que os sujeitos têm do Tipo de Pessoa que tem Doença mental emergiu de forma bifurcada através de duas subcategorias: Pessoa perigosa(comportamento ameaçador) e, Pessoa como outra qualquer (um igual); por último a Concepção que os sujeitos têm da Consequência que tem a Doença Mental para o portador desta enfermidade, onde sobressaíram-se três subcategorias: Carência (portador de carências), Doença que invalida (torna a pessoa incapaz) e, Causa de sofrimento. A maioria dos sujeitos, revelou que o restabelecimento da saúde do enfermo e a sua aposentadoria facilitariam o acompanhamento. Conclusão: as respostas definem um desejo dos sujeitos com relação à recuperação e a possibilidade de oferecer condições dignas de tratamento aos portadores de transtorno mental, através da melhoria das condições financeiras dos mesmos.
\end{abstract}

Palavras-Chave: Doente mental; Cuidador; Representações sociais.

\section{Social Representations of Mental Patient on Perception of the Caregivers}

\begin{abstract}
Constant complaints with regard to hospital psychiatric treatment, by family members of individuals with mental disorders, motivated the question of how would the mentally ill representation for these people. Objective: To know the social representations of mental illness that have the families of psychiatric patients. Method: while qualitative research, we applied a survey questionnaire concepts, opinions and feelings in 29 subjects, with kinship to patients of the Hospital Santa Tereza, Crato, state of Ceará. The data were submitted to content analysis, according to Bardin, as theoretical and methodological framework the Moscovician social representation theory. Data analysis enabled the creation of social representations about mental illness developed by the families of interns in three categories.Results: regarding design that individuals have about mental illness, stood out two subcategories: Moral (deviation from normal behavior) and Mystic (hard to explain); the conception that individuals have the Person type that has emerged from Mental Illness forked shape through two subcategories: Dangerous Person (threatening behavior) and, like any other Person (equal); Finally the conception that individuals have the consequence that has a Mental Illness for the carrier of this disease, where three subcategories stood out: demand (carrier shortages), invalidates Disease (It incapable person) and suffering Cause.Most subjects showed that the restoration of the sick health and your retirement facilitate the monitoring. Conclusion: the answers define a desire of individuals with regard to recovery and the possibility of offering decent treatment to patients with mental disorders, by improving financial conditions thereof.
\end{abstract}

Keywords: Mental Illness; caregiver; Social representations.

\footnotetext{
${ }^{1}$ Psicóloga pela Faculdade Leão Sampaio - FALS. Mestre em Ciências da Educação, Especialista em Saúde Mental pela Faculdade Leão Sampaio - FALS. Email: irineidebraga@ msn.com;

${ }^{2}$ Acadêmica de Medicina pela Universidade Federal do Cariri. E-mail: julianafv@hotmail.com;

${ }^{3}$ Fisioterapeuta pela Faculdade Leão Sampaio, Ceará, Brasil. E-

${ }^{4}$ Psicóloga pela Faculdade de Ciências Humanas - ESUDA;/PE. Especialista em Formação de Professores para o Ensino Superior , pela Faculdade de Juazeiro do Norte . Especialista em Gestão do Trabalho e da Educação na Saúde, pela Escola de Saúde Pública do Ceará .Docente na Faculdade Leão Sampaio - Ceará, Brasil. E-mail: thercia@ leaosampaio.edu.br.
} 


\section{Introdução}

As constantes reclamações com relação ao tratamento mental hospitalar por parte de familiares de indivíduos portadores de transtornos mentais internados em um hospital psiquiátrico do Município do Crato-CE, permitiram o questionamento de como seriam as representações sociais de doente mental para os familiares de usuários, de um programa de atendimento à saúde mental.

Entende-se, porém, que o sujeito constrói significados para o tratamento psiquiátrico, de acordo com os sentidos ou símbolos atribuídos pela sua própria história social (MOSCOVICI, 1978). Assim, um melhor entendimento, da forma como estas pessoas compreendem a sua inserção em um programa de tratamento para doentes mentais, possibilitaria identificar elementos que pudessem orientar a busca de intervenções mais adequadas, para uma maior adesão ao cuidado em saúde mental.

Optamos por iniciar o presente estudo com uma breve retrospectiva histórica que é também social, das formas de tratamento do adoecer psíquico, que vem se consolidando no decorrer dos séculos como conhecimento e prática na assistência ao portador de transtorno mental.

Até a Idade Média, a doença mental era praticamente despercebida como enfermidade e, quando notada, era vista como algo do cotidiano ou como dádiva divina, por meio de significações mágicas e religiosas. A loucura tinha na sociedade uma certa razão, um ingrediente natural que habitava as casas, os povoados e os castelos (FOUCAULT, 1987). Os insanos, assim como os portadores de deficiência mental e os miseráveis, eram considerados parte da sociedade e o principal alvo da caridade dos mais abastados, que assim procuravam se redimir dos seus pecados. Apenas os casos mais graves ou perigosos sofriam segregação pela sociedade, e as recomendações terapêuticas eram: o contato com a natureza, viagens, passeio, repouso, retiro e o teatro, no qual se apresentava ao louco a comédia de sua própria loucura (FOUCAULT, 1979).

No final do século XVIII, acontecimentos históricos repercutiram, na Europa Ocidental, como idéias liberais e libertadoras, passando a se estabelecer como discurso, principalmente na França, onde havia clima de luta pelos direitos de cidadania e, de valorização do homem. Esse movimento revolucionário fez com que o jovem médico Phillipe Pinel ficasse conhecido como aquele que libertou os loucos de suas correntes e os inseriu definitivamente no universo dos enfermos (AMARANTE 1995).

O Tratamento Moral, estabelecido em meados do século XVII, perdeu sua força no final do século XIX. A psiquiatria assumiria posição positivista, centrada na medicina biológica.

Com os avanços na medicina, a psiquiatria se reestabelece como modelo biomédico no tratamento das doenças mentais. Tal modelo biomédico é resultado da influência do paradigma cartesiano onde o corpo é identificado como uma máquina, que pode ser estudada e analisada pelo decompor de suas partes (CAPRA, 1982). 
Na segunda metade do século XX, a quimioterapia tornou-se importante área de pesquisa e prática do tratamento para a loucura. Em 1949, foi descrito o tratamento da excitação maníacoderessiva com o lítio, considerado momento importante na história da psicofarmacologia, que passa a ser uma iniciação de um processo farmacológico para tratamento da doença mental (KAPLAN, 1997).

No Brasil, até meados do século XIX, não houve uma assistência médica específica aos doentes mentais. A inauguração de um primeiro hospital psiquiátrico no Brasil ocorreu somente em 1852, no Rio de Janeiro. Ele recebeu o nome Hospício D. Pedro II, e foi gerenciado pelos religiosos da Santa Casa de Misericórdia. Em 1886, um médico psiquiatra, pioneiramente, ocupou a direção do Hospício (COSTA, 1980).

O tratamento atribuído aos seus internos tinha como objetivo suprimir a loucura. Para isso, alguns princípios deveriam organizar o espaço e a vida asilar. $\mathrm{O}$ isolamento e a vigilância tornaram-se princípios primordiais no tratamento e na segurança dos alienados. A condição de excluir o alienado da sociedade implicava a possibilidade de uma reinserção futura, depois de sua reabilitação através do tratamento oferecido pelo hospício (MACHADO, 1978).

Na segunda metade da década de 80, ocorreu no Brasil a implantação do processo de Reforma Psiquiátrica, que se consolidou norteada por acontecimentos marcantes, como o II Encontro Nacional dos Trabalhadores de Saúde Mental, em Bauru, SP, induzindo novos rumos para a saúde mental. Assim, a preocupação deixou de estar centralizada apenas na instituição psiquiátrica e passou a abranger a condição humana, social, política e cultural do doente mental, abrindo espaço para um questionamento viável e crítico (BEZERRA, 1994).

Dentre as várias iniciativas que emergiram ao longo da década de 90, para implementar as diretrizes propostas pela Reforma Psiquiátrica Brasileira, destacamos o processo de transformação do modelo assistencial, do Serviço de Saúde Dr. Cândido Ferreira (SSCF), localizado em Campinas, SP. Desde 1991, por meio de suas ações de desinstitucionalização e de reabilitação psicossocial, intenciona superar a utilização da internação psiquiátrica como forma exclusiva de tratamento para a doença mental. Esse serviço tem por objetivo possibilitar a emergência no aparecimento de outras vertentes e modalidades de cuidados, visando introduzir os princípios que conduziram à implementação da Reforma Psiquiátrica em Campinas.

O Centro de Atenção Psicossocial CAPS-Estação, integrou-se entre as Unidades pertencentes ao Serviço de Saúde Dr. Cândido Ferreira (SSCF), uma instituição de saúde mental existente no município de Campinas, Estado de São Paulo, desde 1924,, sendo inaugurado em abril de 2000, localizado na região central de Campinas. Esse serviço presta atendimento aos indivíduos com transtornos mentais, encaminhados pelas Unidades Básicas de Saúde, e também pelo próprio SSCF.

A estratégia de base do modelo de assistência do SSCF se constituiu por meio de dois pontos principais: a desospitalização e a criação de ações de reabilitação psicossocial. O Centro de Atenção Psicossocial-CAPS/Estação, como Unidade desse Serviço, integrou essa concepção reabilitadora. 
O intuito desta investigação limita-se a compreender quais os sentimentos e desafios dos familiares de doentes mentais, vinculados ao Centro de Atenção Psicossocial-CAPS,, partindo do pressuposto de que as ações dos indivíduos são orientadas pelas representações estabelecidas no seu cotidiano.

\section{Saúde Mental no Ceará}

O Estado do Ceará tem se mostrado um dos pioneiros na transformação do antigo modelo manicomial para um modelo de assistência psicossocial. O primeiro CAPS do Estado surgiu em novembro de 1991, na cidade de Iguatu. Logo depois vieram os CAPS de Canindé (agosto de 1993), de Quixadá (dezembro de 1993) e de Icó (março de 1995). As transformações nas cidades em que foram implantados tais serviços de atenção psicossocial foram visíveis. Os gastos com internações psiquiátricas diminuíram, e a comunidade avançou em termos de movimentos sociais para a Luta Antimanicomial, configuração de Comissões Municipais de Saúde Mental e para aprovação de Leis Orgânicas Municipais, que levassem em conta os princípios da Reforma Psiquiátrica (SAMPAIO e col., 1998).

Em Sobral-CE, o acolhimento psiquiátrico inicia-se na década de 1970, com a abertura de um serviço pequeno e particular de atendimento psiquiátrico. Em 1974, criou-se a Casa de Repouso Guararapes, atendendo a microrregião de Sobral com 80 leitos de internação. Funcionou nos moldes da psiquiatria clássica, com uma maior clientela de alta cronificação do quadro de enfermidade, com um tempo bem maior de permanência e frequentes reinternações (SILVA e col., 2000).

O hospital psiquiátrico instalado em Sobral, embora com mais de vinte anos de funcionamento, apresentava-se deficitário em termos de recursos terapêuticos. Poucas ferramentas clínicas, reduzindo-se à uma abordagem biofarmacológica, com características de ambiente prisional, com prática de exclusão social. O hospital onerava os cofres públicos e implicava em pouca eficácia terapêutica. Com relação aos internamentos, também era caro ao Sistema Único de Saúde, do que os hospitais gerais localizados em Fortaleza (PEREIRA e ANDRADE, 2001).

No ano 2000, por conta de constantes reclamações de maus-tratos e torturas aos pacientes no hospital Guararapes, a instituição fora descredenciada como prestadora de serviço de ambulatório e internamento ao SUS, sendo instaurada uma re-estruturação do sistema de atenção à saúde mental neste município (RAISM) (SILVA e col., 2000). 


\section{Aspectos históricos das Representações Sociais da Loucura}

Jodelet (1989) no seu estudo sobre representações sociais da loucura, constatou a existência de diversas crenças sobre a transmissão desta enfermidade através de secreções corporais e, analisando com uma maior profundidade tais crenças, a autora demonstrou como sua permanência ou remanescência, com raízes detectadas na teoria dos humores e, cujos fundamentos médicos datam de tempos muito antigos - encontra razão de ser nas ideias simbólicas que estigmatizam o doente. Os conceitos sobre saúde e doença constituem-se enquanto referências para os fazeres terapêuticos, pois suas múltiplas significações determinam condutas, decisões e atitudes com relação ao processo de tratamento.

De acordo com Morant (1998), subjacente a desinstitucionalização das instituições psiquiátricas, parecem prevalecer convicções generalizadas de que, pacientes psiquiátricos parecem um perigo para eles mesmos, para cada um de nós e, mais ainda, para o público em geral. Nesse sentido, investigar as representações sociais de doença mental implica desconstruir estereótipos e analisar, em seu processo constitutivo, a influência das formações ideológicas e do conhecimento supostamente científico.

Jovchelovitch (1998) situa "um símbolo como uma representação de algo produzida por alguém. A força do símbolo reside em sua habilidade para produzir sentido. Ao mesmo tempo que é representação de alguma coisa, o símbolo também representa um sujeito social. De acordo com Arruda (1998), a teoria das representações sociais traz sua contribuição ao estudo da alteridade pela via da cognição, mas também dos afetos, apontando-os como fonte de direcionamento destes contornos, assim como a presença do inconsciente na configuração dos seus desenhos.

A história da loucura pode ser interpretada como a história de sua representação. A evolução da psiquiatria e da assistência prestada ao doente mental indica que a cada modalidade terapêutica proposta, a cada atitude definida diante da loucura, esteve sempre subjacente uma representação de doença mental, como expressão das interpretações hegemônicas que circulam no imaginário social (ALEXANDER e SELESNICK, 1980). A representação da doença implica, portanto, uma determinada visão de mundo, de ciência e de ética, constituindo-se enquanto indicador do grau de desenvolvimento do pensamento científico do grupo ou categoria profissional. De acordo com Arruda (1998), a teoria das representações, posta numa perspectiva diacrônica, revela a mobilidade das construções de alteridade, degelando seu conteúdo negativo e sinalizando seus mecanismos como inerentes ao tratamento da diferença. A história da loucura é também a história da construção da alteridade.

Na antiguidade, a desrazão era encarada como possessão maligna, fruto da ação de forças sobrenaturais, tratadas pela magia e feitiçaria (FOUCAULT, 1968; COE, 1973; TORREY, 1976). A representação da loucura como bruxaria, na era clássica, sofre um lento processo de humanização, 
quando começam a se indagar com relação a seus fatores causais. Esse relativo avanço percebe um retrocesso na Idade Média, quando a insanidade passa a ser significada novamente no campo do misticismo e da demonologia. A satanização dos desviantes será um mecanismo de ancoragem que continuará a ser praticado em momentos históricos posteriores, indicando que no imaginário social representações antigas convivem lado a lado com representações atuais, constituindo-se enquanto passagens de sentidos. De acordo com Morant (1998), as representações da loucura são fluidas, múltiplas e caracterizadas pela não-familiaridade e incerteza.

A renascença representou um momento histórico em que foram dados os primeiros passos em direção a uma concepção secularizada do fenômeno da loucura. O homem passa a conceder grande valor à vida terrena e a crença nos dogmas foi sendo gradativamente substituída por valores derivados da observação e da experimentação (DOBB, 1965, CORVISIER, 1983). O progresso científico, a aquisição de conhecimentos acerca da doença mental, afetaria ou modificaria as representações mais ligadas ao senso comum, baseadas na fé e na crença? No século XVIII, durante o iluminismo, a loucura, então laicizada, penetrou num universo de significações morais sendo posteriormente circunscrita num discurso organicista.

Ao final desse século, ela é olhada sob a primazia da razão médica e transformada em entidade patológica. Na representação da loucura como doença mental, afirmou-se o processo de elaboração da psiquiatria como ciência médica e a constituição de seu objeto. Philippe Pinel levou às últimas conseqüências a representação como doença, afirmando a noção de cura em uma moléstia progressiva, em que se perdia temporariamente a razão e que havia um meio de resgatá-la. A representação médica da doença ou a medicalização do desvio é inerente ao processo constitutivo da psiquiatria e, nesse sentido, as concepções e as representações de cunho científico são necessárias ao exercício profissional e à ruptura instrumental entre o eu-profissional e o outro-doente.

Em fins do século XIX, com Kraeplin e a constituição das entidades nosográficas (esquizofrenias, parafrenias, etc.), o insano ganha definitivamente seu estatuto científico; a representação patológica do louco é associada a uma imagem de ameaça ao convívio social. Seu confinamento espacial é reforçado por uma barreira temporal, crônica, definitiva, o sanatório psiquiátrico. As representações modernas de doença mental foram predominantemente encenadas, tendo, como palco e cenário, o hospício. A orientação organicista em psiquiatria resultou na transferência dos conceitos e dos métodos que foram considerados úteis no tratamento da doença orgânica para o campo dos distúrbios emocionais e comportamentais. (BERLINGUER, 1976; JERVIS, 1977). Freud com suas hipóteses sobre o aspecto inconsciente da dinâmica psíquica possibilita assim uma melhor compreensão das formas ditas sadias e patológicas. A psicanálise contribuiu para a representação da doença mental, como conseqüência de traumas infantis e como decorrência da ação de mecanismos inconscientes. Com o desenvolvimento de pesquisas sobre as relações humanas em processos grupais, começa-se a perceber a doença na interação entre o paciente e 
seu meio social, o grupo familiar. É a partir daí que se estrutura o conceito de porta-voz, o doente como representante da doença do grupo familiar, como significante da neurose coletiva (PICHON, 1982).

Neste século, a busca incessante pela compreensão da doença mental levou a que, nos diagnósticos formulados nos serviços de psiquiatria, continuasse subjacente a indagação pelos sintomas, pela etiologia, pela possibilidade de se explicar o não usual ou o inefável. Avaliar alguém como ser patológico mentalmente é articular significados sociais complexos, um sistema de regras e uma gramática do desejo, que, em outras sociedades ou mesmo em contingências diferentes numa mesma sociedade, poderiam ser interpretados diferentemente. Feitiçaria, magia, saber divinatório, heresia, patologia, a verdade é que a loucura ou a doença mental sempre foi um fenômeno social interpretado e representado de diversas maneiras, de acordo com o contexto e o momento histórico vivido. A assistência oferecida aos mentalmente enfermos esteve sempre calcada nessas representações, tendo como função sua legitimação. De que modo as representações historicamente engendradas e que circulam no senso comum afetam as práticas dos profissionais de saúde mental? Ou de outro modo, quais representações circulam entre os familiares dos usuários de um Centro de Atenção Psicossocial - no estudo em questão, e como incorporam os diversos saberes sobre a loucura produzidos ao longo da história e veiculados durante o processo de convivência com o doente mental?

\section{O Papel da Assistência Familiar para o portador de Transtorno Psíquico}

A família tem ocupado lugar privilegiado em discussões que envolvem as diversas instâncias do poder público. Os programas de atenção à saúde buscam recolocar a unidade familiar em uma posição de responsabilidade pelo cuidado de seus membros e torná-la agente de transformação nos diversos cenários da assistência, pois, geralmente é a família a cuidadora e fonte de apoio aos seus membros, arcando com a responsabilidade de continuar controlando e cuidando da saúde destes, independente da faixa etária e do tipo de patologia em questão (ANDRADE et al, 1997).

No campo da história da Psiquiatria, buscando explicação para o fenômeno do adoecimento psíquico, a família era considerada a causa do adoecer, pois a alienação poderia ter influência de uma educação corrompida e do desregramento no modo de viver do sujeito (PESSOTI, 1996). O tratamento, então, consistia em afastar a família do doente para que este - alvo do confinamento pudesse libertar-se do quadro patológico; daí, os pacientes psiquiátricos ficaram - durante décadas isolados em hospitais psiquiátricos, estando permanentemente sob a vigilância de profissionais de saúde, dentre eles, os alienistas.

A instituição da psiquiatria no Brasil utilizou como referencial a prática do alienismo francês e também excluiu a família do tratamento do sujeito em sofrimento; a ação de segregar seu ente, a partir 
da autorização do internamento no manicômio significava o desfecho do problema daquele núcleo familiar. Havia uma transferência total tanto do sujeito quanto de seus conflitos para o hospital psiquiátrico, ficando os familiares esperançosos quanto ao poder de cura atribuído ao disciplinamento e à terapia medicamentosa rigorosa ofertada naquele lugar. Essa forma de tratamento deixou como marca o isolamento e a segregação social que permeiam a saúde mental até os dias atuais.

A participação da família no processo terapêutico do sujeito com transtorno psíquico teve início a partir dos movimentos de Reforma Psiquiátrica, em 1979, ocasião em que necessitava-se de um redirecionamento das práticas de saúde mental, até então, pouco eficazes. O ideário de Reforma Psiquiátrica propunha que se compreendesse o sujeito como construtor de sua história, respeitando sua singularidade e favorecendo-lhe o aprendizado e a vivência com outras formas de relação, oferecendo sentido para sua existência e não mais utilizando como parâmetro o retorno à normalidade ou a cura de seu quadro psiquiátrico (MORENO e ALENCASTRE, 2004).

Souza e Scatena (2005) enfocam que a Reforma Psiquiátrica trouxe, além do novo olhar para a assistência até então dispensada ao chamado "doente mental", uma certa desassistência com a devolução do sujeito à família sem o devido conhecimento das suas reais necessidades e condições, em termos materiais, psicossociais, de saúde e qualidade de vida. Não houve um repensar de práticas de saúde anteriores à esta mudança de atenção; profissionais de saúde mental sequer atentaram para o fato de que, se eles mesmos buscavam a reconstrução de saberes e práticas, como os familiares poderiam estar preparados para essa nova roupagem do modo de promover o acompanhamento do sujeito? De que maneira a família poderia ser apoiada e como os agentes da saúde mental ofertariam este apoio?

Com base nesse novo olhar paradigmático, a família viu-se despreparada para acolher o sujeito em sofrimento, limitando-se a ouvir suas queixas, seu pedido de ajuda, sentindo-se impotente frente às crises próprias de cada momento vivenciado pelo indivíduo.

O Relatório Final da 3a. Conferência de Saúde Mental (BRASIL, 2001) registrou que, à medida em que houvesse a construção de serviços alternativos (CAPS, NAPS, Casas-abrigo), estes deveriam programar estratégias de ação dirigidas aos familiares e ao usuário, comprometendo-se com os projetos de inserção social e respeitando as subjetividades. Dessa forma, a família passou a ser chamada a participar de organizações civis que buscassem garantir a conscientização de seus direitos e viabilizassem o exercício pleno de sua cidadania (MORENO e ALENCASTRE, 2004).

Todavia, os familiares que têm entre seus membros uma pessoa em sofrimento psíquico mostram-se, na maioria das vezes, ansiosos e impotentes diante das dificuldades, sentem-se solitários ao caminhar em busca de melhores condições de saúde para seu ente acometido pela doença, necessitando de apoio profissional para dar continuidade ao processo terapêutico do sujeito. A atuação da equipe de saúde mental junto à família torna-se salutar no sentido de promover o acolhimento 
familiar e dar suporte ao portador de transtorno psíquico, através da integração de suas ações de saúde, vislumbrando o caráter integral e humanizador do atendimento.

É consenso que, quando a família é apoiada e orientada pelos profissionais de saúde mental, torna-se elo decisivo no processo de desinstitucionalização e reinserção social do portador de transtorno psíquico, emergindo dela a responsabilidade pela manutenção deste sujeito fora da instituição psiquiátrica, o que reforça a necessidade urgente de estratégias de saúde voltadas exclusivamente para o acolhimento da unidade familiar pelos profissionais no que se refere ao convívio com o indivíduo em sofrimento.

Contudo, a família enfrenta dificuldades para conviver com o portador de sofrimento psíquico, talvez por não ter suficiente conhecimento sobre a doença vivenciada pelo seu familiar, resultando algumas vezes em exclusão social de todos os membros daquele núcleo familiar, pelo preconceito que a sociedade impõe. Isto gera mudança de hábitos, havendo uma maior tensão na convivência, ocorrem restrição de visitas, diminuem as saídas para passeios, o que dificulta o processo terapêutico do sujeito. Por esse motivo, os serviços de saúde mental também passaram a oferecer atenção aos familiares, compondo parcerias em uma nova forma de cuidado, utilizando principalmente as estratégias de grupo para possibilitar trocas de experiências, bem como de orientação de como lidar e conviver com o paciente com transtorno mental (MORENO e ALENCASTRE , 2004).

Se não é mais aceitável estigmatizar, excluir e recluir os loucos, de igual forma não se pode limitar o paradigma da Reforma Psiquiátrica à desospitalizá-los e devolvê-los aos familiares, como se a unidade familiar tivesse a resolutividade dos conflitos advindos da doença mental e do convívio com o portador de transtorno (GONÇALVES e SENA, 2001). Requer maiores reflexões críticas dos significados de doente/doença mental para todas as esferas sociais - profissionais de saúde, família, sociedade - para que haja mudança de pensamento, de práticas de saúde e de formação de profissionais capazes de serem agentes de mudança e de cidadania, louvando o respeito e a ética com o direito do homem de ser humano.

Identificar os sentimentos dos familiares, na convivência com portadores de doença mental internados na Casa de Saúde Santa Tereza, no município do Crato, estado do Ceará, no período de Agosto a Setembro de 2014 foi o objetivo principal do presente estudo.

Trata-se de uma entidade prestadora de serviços particulares e serviços em convênio com o Sistema Único de Saúde, que atende principalmente a pessoas portadoras de enfermidades mentais.

Este estudo aproximou-se da perspectiva teórica do conceito de representação social, tendo como principais autores Serge Moscovici e Denise Jodelet. A representação social foi abordada como modalidade de conhecimento particular que tem por função a elaboração de comportamentos e a comunicação entre os indivíduos (MOSCOVICI, 1978). A noção de representação social se constitui na maneira de interpretar e de pensar a realidade cotidiana, ou seja, uma forma de conhecimento social (JODELET, 1988). 
Esta pesquisa, em função de seu objeto, define-se por um método, configurado por Moscovici (1961), de análise das representações sociais, tendo por base a sistematização das práticas discursivas.

Spink (1993) recomenda o uso de múltiplos métodos e de comparação intermétodo, "que suscita interessantes reflexões sobre a polimorfia intrínseca das representações sociais". No caso da presente investigação, foi aplicado um questionário em que a coleta de dados se dá no interior de uma ordem de fenômenos considerados pertinentes.

Por outro lado, quando Spink (1989) propõe novos caminhos metodológicos, requisito imprescindível para que sejam acessadas as representações e suas condições de produção, pensou-se no questionário enquanto uma forma de sistematizar um conjunto de falas e práticas discursivas ao qual se tem acesso de uma forma assistemática.

A população objeto desta investigação, contou com uma amostra representativa dos familiares dos pacientes com diagnóstico de doença mental, internados no Hospital, num total de 29 sujeitos maiores que 18 anos.

Os dados foram obtidos através de entrevistas semi-estruturadas realizadas individualmente pela pesquisadora e um Teste de Associação Livre de Palavras. Trata-se de um tipo de investigação aberta que se estrutura na evocação de respostas dadas a partir de quatro estímulos indutores, o que permite colocar em evidência universos semânticos de palavras que agrupam determinadas populações. Esse instrumento já foi experimentado e validado em pesquisas realizadas sobre representações sociais (ROSA, 1999). Segundo Abric (1994), este instrumento permite a "atualização de elementos implícitos ou latentes que seriam perdidos ou mascarados nas produções discursivas" (p.66).

Optou-se por trabalhar com o material obtido através da análise do conteúdo (BARDIN, 1977). A técnica de análise de dados utilizada na análise do conteúdo foi a da análise temática, considerando uma das formas que melhor se adequa à investigação qualitativa das pesquisas em saúde (MINAYO, 1999).

As respostas foram agrupadas por grau de semelhança. No contexto da análise, foi explorado cada item do questionário com os familiares, sujeitos deste estudo, de forma a aprofundar-se a discussão sobre cada assunto. 


\section{Resultados e Discussão}

Tabela 1 - Tempo de Acompanhamento dos Pacientes. Crato-CE, 2014.

\begin{tabular}{c|c|c}
\hline $\begin{array}{c}\text { Tempo de } \\
\text { Acompanhamento }\end{array}$ & $\mathbf{n}$ & $\mathbf{f}(\boldsymbol{\%})$ \\
\hline Até 4 anos & 9 & 31,0 \\
\hline $4-18$ anos & 5 & 17,3 \\
\hline $8-12$ anos & 6 & 20,7 \\
\hline $12-16$ anos & 5 & 17,3 \\
\hline$>16$ anos & 4 & 13,7 \\
\hline TOTAL & 29 & 100,0 \\
\hline
\end{tabular}

Fonte: Hospital Santa Tereza, Crato-CE/2014

Pudemos constatar que o tempo de acompanhamento dos enfermos pelos sujeitos foi bastante variável. De acordo com a tabela acima 9 sujeitos (31\%) acompanham os pacientes há 4 anos ou menos, 11 sujeitos (38\%) fizeram este acompnhamento entre 4 e 12 anos e 9 sujeitos (31\%) já fazem este acompanhamento há 12 anos ou mais.

A literatura (KOGA e FUREGATO, 1998) nos informa que o familiar vai se desgastando em conviver com a pessoa portadora de transtorno mental, acarretando sobrecarga física e emocional, privando-se da sua própria saúde para poder prestar assistência adequada ao enfermo sob sua guarda. Assim, o tempo de acompanhamento parece funcionar como um reforçador negativo para este tipo de trabalho.

Tabela 2 - Sentimentos relativos ao Acompanhamento dos Pacientes. Crato-CE, 2014.

\begin{tabular}{l|c|c}
\hline \multicolumn{1}{c|}{ Sentimentos } & $\mathbf{n}$ & $\mathbf{f}(\%)$ \\
\hline Manifestaçoes físicas & - & - \\
\hline Cansaço & 13 & 9,7 \\
\hline Nojo & 03 & 2,2 \\
\hline O paciente como um fardo & 06 & 4,5 \\
\hline $\begin{array}{l}\text { Manifestações Psico- } \\
\text { aftivas }\end{array}$ & - & - \\
\hline Decepção & 06 & 4,5 \\
\hline Doação sem retorno & 06 & 4,5 \\
\hline Medo & 15 & 11,4 \\
\hline Vergonha & 09 & 6,7 \\
\hline
\end{tabular}




\begin{tabular}{l|c|c}
\hline Impaciência & 16 & 12,0 \\
\hline Peso da responsabilidade & 10 & 7,5 \\
\hline Insegurança & 14 & 10,6 \\
\hline Angústia & 10 & 7,5 \\
\hline Raiva & 08 & 6,0 \\
\hline Tristeza & 17 & 12,9 \\
\hline TOTAL & 133 & 100,0 \\
\hline
\end{tabular}

Fonte: Pesquisa própria, Crato-CE/2014

A família tem poucas respostas para as suas inquietações, por isso fica nervosa, ansiosa e com medo, como é possível perceber nos sentimentos apresentados na tabela acima. Além disso há uma sobrecarga física em função da convivência com o doente mental, pois é necessário que os integrantes "sadios" e com mais disponibilidade da família dêem conta das atividades cotidianas, inclusive, muitas vezes, aquelas atribuídas ao doente mental antes da exacerbação dos sintomas. Também parece haver reflexos nos cuidados com os filho, principalmente se ainda são crianças. Daí o surgimentos de manifestações físicas como "cansaço" e "paciente como um fardo".

Oliveira e Jorge (1998), acreditam que o comportamento imprevisível do doente mental debilita as expectativas sociais e origina incerteza e insegurança nos seus familiares. Assim ficam mais vulneráveis ao aparecimento de sentimentos desagradáveis como medo, vergonha, raiva, tristeza dentre outros descritos na tabela acima.

Há uma diversidade de sentimentos desencadeados pela doença mental. Prevaleceu, no nosso estudo o sentimento de tristeza, que indica uma representação do enfermo como um coitado, numa atitude de aparente desconhecimento do seu potencial para reagir diante de situações adversas. Outros sentimentos acabam por refletirem uma ambigüidade presente nas representações. Assim, medo, peso da responsabilidade, angústia e impaciência ... Os familiares, embora vivendo um laço afetivo mais próximo com o enfermo, não parecem preparados para enfrentarem tantos sentimentos. Segundo Irving (1978) a forma de lidar com os próprios sentimentos tem sido considerada um ferramenta a mais na compreensão da doença mental.

Portanto a tarefa de tratar precisa ser encarda de uma forma positiva visando encontrar-se maneiras satisfatórias de ajudar e proporcionar meios adequados a evolução do quadro clínico do enfermo. 
Descrições da Categoria e Subcategorias das Representações sociais de Doente mental pelos sujeitos

A CATEGORIA 1 - (CDM): refere-se a Concepção que os sujeitos têm de Doença mental, onde sobressaíram-se duas subcategorias: Moral e Mística.

Moral - onde a doença mental é representada como uma inter-relação entre o indivíduo e a sociedade, isto é, onde observa-se uma referência a um conjunto de normas que legitima e ordena as condutas sociais, sendo então encarada como um desvio em relação ao comportamento aceito socialmente como normal: “... é um problema de cabeça que prejudica os outros..."; ”... não tem senso das coisas...”; “...não tem nenhum limite...”; “..ninguém confia...”; “..pessoa fora do seu sentido normal...".

Mística:-.Este grupo de respostas contribui para a representação de Doença mental como algo difícil de explicar. “...algo paranormal...”; “...se existir espirito baixa nele...”; “..uma coisa horrivel, fora de série...”; “...não tem explicação...”;”... a gente aceita por ser vontade de Deus...”. Segundo Vietta e Kodado (2001), a doença mental sempre foi um fenômeno social interpretado e representado de diversas maneira, de acordo com o contexto e o momento histórico vividos, tais como a feitiçaria, a magia ou o saber supostamente divino.

Segundo Moscovici (1978) “... os dados que a maioria das pessoas dispõe para responder a uma pergunta são, em geral, simultaneamente insuficientes e superabundantes",ou seja, os indivíduos podem conhecer pouco sobre um determinado assunto, embora possam produzir referências abundantes sobre este, quando relacionado com outros assuntos. No nosso estudo, as representações de doença mental, nesta categoria, caracterizou-se por um saber ao mesmo tempo lógico e deficiente.

A CATEGORIA 2 - (CTP): refere-se a Concepção que os sujeitos têm do Tipo de Pessoa que tem Doença mental, onde sobressaíram-se duas subcategorias: Pessoa perigosa e Pessoa como outra qualquer.

Pessoa perigosa - este grupo de respostas ressalta a conseqüência social do comportamento desviante considerado na subcategoria anterior, neste caso, a doença mental é representada como ameaçadora, refletindo uma rejeição aos portadores desta enfermidade: “...pessoa que sai fora do sentido...”; “...fica ouvindo vozes e vendo gente matar..”;”...incontrolável...”; “...fraqueza no juizo...”; “...um pessoa nervosa...”; “...querendo matar a sua mãe...”; “...pessoa fraca que não tem mente..."; "... a pessoa está bem e depois não está mais...( )... fica louco...”; ”... não tem noção das coisas...”; “...desespera e perde o juizo...”; “...faz coisas sem sentir...”; “...ninguém consegue controlar...”; “...não saber o que fazer...”; “...não sabe o que está fazendo...”; “...não tem juizo nenhum...”; “...pessoa doida demais...”.

Considerando os depoimentos dos sujeitos, percebemos que há uma sobrecarga da família em especial diante da agudização dos sintomas. Fica evidente nas falas, as mudanças de comportamentos dos doentes mentais, situação essa de difícil entendimento tanto para a família quanto para a sociedade 
em geral. Oliveira e Jorge (1998, p. 381) reforçam estas idéias quando afirmam que "o desgaste, tensões e conflitos causados por uma pessoa mentalmente perturbada, constituem os maiores problemas que a família enfrenta. A imprevisibilidade do paciente é outra fonte de tensão em casa". Toda mudança decorrente da psicose, mobiliza muito os familiares, até porque há um certo desconhecimento dos mesmos ao que fazer e como cuidar de uma pessoa com essas características.

Pessoa como outra qualquer: Neste grupo de respostas a pessoa portadora de doença mental é representada como um igual, uma pessoa como outra qualquer, diferindo apenas em termos da intensidade em que necessitam de cuidados: “..são pessoas iguais a nós...”; “...eles são pessoas normais e a gente tem que aceitar...”; “...são pessoas iguais a mim...”; “...pessoa como nós que tem mais dificuldades.. ";

A CATEGORIA 3 - (CCO): refere-se a Concepção que os sujeitos têm da Consequência que tem a Doença mental para o portador desta enfermidade, onde sobressaíram-se três subcategorias: Carência, Doença que invalida e causa de sofrimento.

Carência - Esta subcategoria apresenta representações de Doente mental como alguém a quem falta algo, um indivíduo portador de carências, que necessitam de maior cuidado: “... são pessoas indefesas...”; “... pessoa que precisa muito de afeto...”; “...precisa de socorro...”; “...deseja muito cuidado...”; “...precisa se tratar..”; “...pessoa com problemas...”; “...é uma pessoa doente...”; “..pessoa que tem uma deficiência...”,; “...precisa de amor e carinho...”,; “....gente que fica sem saber de nada...”; “... são pessoas que precisam de cuidado...

Doença que invalida - neste caso, a doença mental é representada como um mal endógeno que torna a pessoa inoperante, incapaz de lidar com questões vitais: “...pessoa que já nasce doente...”; “...problema de loucura....”;”...não tem cura...”; “...melhora e piora...”; “...é uma fraqueza dos nervos...”; “..não é uma pessoa normal...”; “....não muda nunca...”; “...representa aquele que não tem mais cura...”;".. a pessoa fica fraca...”; “...uma pessoa sem sentido...”; “...pessoa assim não é nada... "; "... é mais doente que um cego...".

Percebemos nos discursos dos sujeitos que existem algumas dificuldades de entendimento da doença mental, bem como da instabilidade afetiva que esta acarreta, fatores estes que interferem na convivência com a pessoa portadora de transtorno psiquiátrico. Parece também entenderem que sofrimento mental possui uma carcterística de cronicidade e incurabilidade. Moreno (2000), coloca que o diagnóstico da doença é muito valorizado pelo familiar, mas na maioria das vezes, ele não possui o entendimento da patologia propriamente dita.

Causa de sofrimento - Este grupo de respostas ressalta o estigma que representa a doença mental para a sociedade. Suas atitudes e comportamentos de certa forma "fora dos padrões' esperados socialmente, constituem um álibi para a sua marginalização: “..uma tristeza para a família...”; “...um desgosto...”; “...sofrimento par todos...”;”...representa sofrimento...”; “...necessita ter muita 
paciência...”; “...necessita coragem para poder lutar...”; .pessoa que já nasce doente...”; “...uma tristeza para todos...”; “...é a pior tristeza que existe porque é para sempre...”; ”... eu peço força a Deus...”; “...tem dia que é muito difícil...”; “...é ruim demais...”; “...é de preocupação...”; “...uma pessoa condenada...”; “...a pior coisa do mundo...”;”...uma tristeza maior pra quem tem...”; “...muito sofrimento... ”; “...loucura é um sofrimento...”; “... é terrível agüentar...”;

Nas expressões utilizadas pelos sujeitos, observa-se uma demonstração de sacrifício do familiar em cuidar do doente mental psicótico com instabilidade afetiva. Freitas e Mendes (1999) ressaltam que o cuidado de pessoas em condições crônicas exige a readaptação da família e um investimento emocional cotidiano da mesma, para que a adaptação ocorra de maneira menos traumática possível.

\section{Sobre o trabalho de acompanhamento dos sujeitos pela família}

Tabela 3 - O Que Facilitaria a vida dos acompanhantes de pessoas com Enfermidade Mental.

\begin{tabular}{l|c|c}
\hline $\begin{array}{l}\text { O que facilitaria a vida do } \\
\text { acompanhante }\end{array}$ & N & $\mathbf{f ( \% )}$ \\
\hline Aposentadoria do enfermo & 8 & 27,6 \\
\hline Cooperação do enfermo & 5 & 17,2 \\
\hline $\begin{array}{l}\text { Restabelecimento da saúde do } \\
\text { enfermo }\end{array}$ & 10 & 34,6 \\
\hline $\begin{array}{l}\text { Maior disponibilidade de tempo do } \\
\text { acompanhante }\end{array}$ & 2 & 6,8 \\
\hline Outro & 4 & 13,8 \\
\hline TOTAL & 29 & 100,0 \\
\hline
\end{tabular}

Fonte: Pesquisa própria, Crato-CE, 2014

Observe-se que, a maioria dos sujeitos $10(34,6 \%)$, revelou que o que facilitaria a vida do acompanhante dos doentes mentais seria o restabelecimento de sua saúde; a aposentadoria do enfermo foi citada por $8(27,6 \%)$ sujeitos. As respostas definem um desejo dos sujeitos com relação à recuperação e a possibilidade de oferecer condições dignas de tratamento através de uma melhoria das condições financeiras dos mesmos. São mencionados também a cooperação do enfermo $(17,2 \%)$ e uma necessidade de maior disponibilidade de tempo ( $6,8 \%)$ como fatores facilitadores do trabalho de acompanhamento.

Estudos de Koga e Furegato (1998) tratam das sobrecargas que a família passa em decorrência da convivência com o doente mental, e as classificam como financeiras nas rotinas familiares, tais como doença física, emocional, alterações das atividades de lazer e relações sociais. 
Tabela 4 - Desafios na vida de acompanhante de pessoa com enfermidade mental.

\begin{tabular}{l|c|c}
\hline Desafio & $\mathbf{n}$ & $\mathbf{f}(\boldsymbol{\%})$ \\
\hline Saúde do enfermo & 14 & 48,3 \\
\hline Cooperação do enfermo & 5 & 17,2 \\
\hline $\begin{array}{l}\text { Melhoria das condições de moradia do } \\
\text { enfermo }\end{array}$ & 4 & 13,8 \\
\hline Encontrar a ajuda certa & 2 & 6,9 \\
\hline Melhoria da situação financeira & 2 & 6,9 \\
\hline Outro & 2 & 6,9 \\
\hline TOTAL & & 100,0 \\
\hline
\end{tabular}

Fonte: Pesquisa própria, Crato-CE, 2014

Alguns dos sujeitos se reportaram a convivência cotidiana com o doente mental como geradora de dificuldades. Principalmente quando há uma exacerbação dos sintomas da psicose, onde a pessoa enferma exige muito mais disponibilidade dos seus acompanhantes.

Conforme Moreno (2000) , há uma maior tensão na convivência, a família procura se isolar, ocorre restrição de visitas, diminuem as saídas para passeios, ou seja, o período de lazer diminui. Neste sentido, torna-se compreensível que um dos desafios mais citados pelos sujeitos tenha sido a saúde do enfermo (48,3\%), seguida de cooperação do enfermo (17,2 \%). As outras respostas também dizem respeito a uma situação de minimização da mobilização dos membros da família em torno do paciente e do seu conseqüente desgaste.

Para Cavalheri (2002), quando a família possui um membro com uma doença mental, toda ela acaba mobilizando-se inteiramente. O desgaste é agravado quando se trata de uma doença de ação prolongada, com freqüentes casos de piora dos sintomas e quando é considerada incapacitante.

\section{Considerações Finais}

Parece haver uma diversidade de sentimentos desencadeados pela doença mental nos familiares acompanhantes dos sujeitos. Prevaleceu, no nosso estudo o sentimento de tristeza, que indica uma representação do enfermo como um coitado, numa atitude de aparente desconhecimento do seu potencial para reagir diante de situações adversas. Outros sentimentos acabam por refletirem uma ambigüidade presente nas representações. Assim, medo, peso da responsabilidade, angústia e impaciência ... Os familiares, embora vivendo um laço afetivo mais próximo com o enfermo, não parecem preparados para enfrentarem tantos sentimentos.

As representações sociais acerca de doença mental, elaboradas pelos familiares dos internos, evidenciaram três categorias: 1 . Concepção que os sujeitos têm de Doença mental, onde sobressaíram- 
se duas subcategorias: Moral e Mística; 2. Concepção que os sujeitos têm do Tipo de Pessoa que tem Doença mental, onde sobressaíram-se duas subcategorias: Pessoa perigosa e Pessoa como outra qualquer; e 3. Concepção que os sujeitos têm da Consequência que tem a Doença mental para o portador desta enfermidade, onde sobressaíram-se três subcategorias: Carência, Doença que invalida e Causa de sofrimento.

Nas expressões utilizadas pelos sujeitos, observa-se uma demonstração de sacrifício do familiar em cuidar do doente mental psicótico com instabilidade afetiva. Freitas e Mendes (1999) ressaltam que o cuidado de pessoas em condições crônicas exige a readaptação da família e um investimento emocional cotidiano da mesma, para que a adaptação ocorra de maneira menos traumática possível.

Outras informações verificadas disseram respeito ao trabalho de acompanhamento propriamente dito. Nesse sentido, os dados são reveladores de uma demanda no sentido de melhoria das condições do trabalho de acompanhamento da pessoa portadora de doença mental.

As respostas definiram um desejo dos sujeitos com relação à recuperação e a possibilidade de oferecer condições dignas de tratamento através de uma melhoria das condições financeiras dos mesmos.

O desafio mais citado pelos sujeitos foi o restabelecimento da saúde do enfermo, seguida da cooperação do enfermo. Alguns dos sujeitos se reportaram a convivência cotidiana com o doente mental como geradora de dificuldades, principalmente durante as crises, quando há uma exacerbação dos sintomas da psicose. Nestas ocasiões a pessoa enferma exige muito mais disponibilidade dos seus acompanhantes. As outras respostas também dizem respeito a uma situação de minimização da mobilização dos membros da família em torno do paciente e do seu conseqüente desgaste.

Sabemos que ter instituições para a reclusão total ou parcial dos pacientes não é suficiente, tornando-se necessário também fazer o possível para orientar a família e ajudá-la nos encaminhamentos necessários para que ela crie condições para que seus problemas sejam minimizados. É verdade que os recursos disponíveis não são suficientes para todos, mas igualmente é verdade que uma comunidade organizada tem maiores possibilidades de conseguir um mínimo de infra estrutura, para lidar com uma problemática tão importante, quanto é a saúde mental. $\mathrm{O}$ acesso a uma aposentadoria ou o licenciamento do familiar cuidador, são direitos que podem ser exigidos por um grupo organizado e assim minimizar em muito, alguns problemas ligados as dificuldades de acompanhamento do enfermo com doença mental.

Os estigmas e preconceitos gerados pelo desconhecimento e pela falta de condições de tratamento adequado ao doente mental é uma lembrança constante da necessidade de programas efetivos de educação em saúde mental. A nossa investigação constatou, uma série de fatores que evidenciam essa necessidade: Desde o desconhecimento dos familiares sobre esta enfermidade, 
evidenciada através de suas representações sociais, até a necessidade de um suporte financeiro complementar, advindo de uma aposentadoria para estes pacientes.

Portanto concluímos que é urgente a implantação de um programa educativo que, dentre outras coisas, atenue os aspectos negativos da doença mental perante a sociedade, bem como que se estimule a comunidade para se organizar visando solicitar às autoridades, um programa que atenda as necessidades assistenciais destes enfermos, minimizando as dificuldades de acompanhamento evidenciadas neste estudo.

\section{Referências}

ABRIC, J. C. Pratiques sociales et représentations. Paris: Presses Universitaires de France, 1994.

ALEXANDER, F.G. \& SELESNICK, s.t. - História da Psiquiatria: uma Avaliação do Pensamento e da Prática desde os Tempos Primitivos até o Presente. Ibrasa, São Paulo, 1980.

AMARANTE, P. Loucos pela vida: a trajetória da reforma psiquiátrica no Brasil. Rio de Janeiro (RJ): SDE/ENSP; 1995.

ANDRADE, O.G. et al. Como os enfermeiros avaliam o cuidado/cuidador familiar. Revista Gaúcha de Enfermagem. v.18, n.02, 1997. p.123-132.

ARRUDA, A. (org.) - Representando a Alteridade. Vozes, Rio de Janeiro, 1998.

BARDIN, L. Análise de Conteúdo. Lisboa: Edições 70; 1977.

BERLINGUER, G. - Psiquiatria e Poder. Interlivros, Belo Horizonte, 1976.

BEZERRA, B Jr. De médico, de louco e de todo mundo um pouco: o campo psiquiátrico no Brasil dos anos 80. In: Guimarães R, Tavares R, organizadores. Saúde e sociedade no Brasil dos anos 80. Rio de Janeiro (RJ): Relume - Dumará; 1994. p. 171-91.

BRASIL. Instituto Brasileiro de Geografia e Estatística, 2000.

CAPRA, F. O ponto de mutação. $6^{a}$ ed. São Paulo (SP): Cutrix; 1982.

CAVALHERI, S.C. Acolhimento e orientação à família. Mesa redonda: importância da família na saúde mental, 2002. Disponível em <http://www.sppc.med.br/mesas/silvana.htm> . Acesso em 22.10.2002.

COE, R.M. - Sociologia de la Medicina. Alianza, Madrid, 1973.

CONSELHO NACIONAL DE SAÚDE. Resolução No. 196/96. Diretrizes e normas regulamentadoras de pesquisas envolvendo seres humanos. Disponível em < http://www.ufpr/index/cepsh> Acesso em 26 abr. 2004.

CORVISIER, A. - História Moderna vol. 2. Círculo do livro, Rio de Janeiro, 1983. 
COSTA, JF. História da Psiquiatria no Brasil. $3^{\text {a }}$ ed. Rio de Janeiro (RJ): Campos; 1980.

DOBB, M. - A Evolução do Capitalismo. Zahar, Rio de Janeiro, 1965.

FREITAS, M.C e MENDES, M.N.R. Condições Crônicas de Saúde e o cuidado de enfermgem . Revista Ltino Americana de Enfermagem. v.7, n.5, p.131-133, 1999.

FOUCAULT, M. História da loucura na Idade Clássica. 2a ed. São Paulo (SP): Perspectiva; 1987.

Microfísica do Poder. 10ª ed. Rio de Janeiro (RJ): Graal; 1979.

Doença Mental e Psicologia. Tempo Brasileiro, Rio de Janeiro, 1968.

GONÇALVES, A.M.; SENA, R.R. A reforma psiquiátrica no Brasil: contextualização e reflexos sobre o cuidado com o doente mental na família. Revista Latino-Americana de Enfermagem. v.9, n.2, 2001. p.48-55.

IRVING, S. - Enfermagem Psiquiátrica Básica. Saunders Co., Rio de Janeiro, 1978.

JERVIS, G. - Manual Crítico de Psiquiatria. Anagrama, Barcelona, 1977.

JODELET, D. - Madness and Social Representation. Living with the Mad in one French Community. Philippness, Califórnia, 1989.

JOVCHELOVITCH, S. - Redescobrindo o Outro, In: Arruda, A. (org.): Representando a Alteridade. Vozes, Rio de Janeiro, 1998.

KAPLAN, I.H, SADOCK JB, FREEDMAN MA. Compêndio de Psiquiatria: ciências do comportamento e psiquiatria clínica. $7^{\text {a }}$ ed. Porto Alegre (RS): Artes Médicas; 1997.

KOGA, M. e FUERGATO, A.R. Convivência com a pessoa esquisofrênica: sobrecarga familiar. In: LABATE, R.C. (org.). Caminhando para a assistência integral. Ribeirão Preto: Scala, 1998.

MACHADO, R. Da (n)ação da norma. Medicina social e constituição da psiquiatria no Brasil. Rio de Janeiro (RJ): Graal; 1978.

MORENO, V. Vivência do familiar da pessoa em sofrimento psíquico. Ribeirão Preto: USP 2000. Tese apresentada ao Programa de doutorado Interunidades das escolas de enfermagem de Ribeirão Preto e São Paulo, Universidade de São Paulo, 2000.

MOSCOVICI, S. A representação social da psicanálise. Rio de Janeiro (RJ): Zahar; 1978.

JODELET, D. Representação Social: Fenômenos, Conceitos e Teoria. Rio de Janeiro (RJ): Fundação Getúlio Vargas; 1988.

MINAYO, M.CS. O desafio do conhecimento: pesquisa qualitativa em saúde. $6^{a}$ ed. São Paulo (SP): Hucitec; 1999.

MORANT, N. \& ROSE, D. - Loucura, Multiplicidade e Alteridade, In: Arruda, A. (org.): Representando a Alteridade. Vozes, Rio de Janeiro, 1998. 
MORENO, V.; ALENCASTRE, M.B. A família do portador de sofrimento psíquico e os serviços de saúde mental: um estudo de caso. Acta Scientiarum Health Sciences. Maringá, v.26, n.1, 2004. p.175-181.

MOSCOVICI, S. - La Psychanalyse, son Image et son Public. P.U.F., Paris, 1961.

MOSCOVICI, S. - A Representação Social da Psicanálise. Zahar, Rio de Janeiro, 1978.

PEREIRA, M. F. Damião: um grito de socorro e solidão. In: OLIVEIRA SILVA, M. V. A instituição sinistra: mortes violentas em hospitais psiquiátricos no Brasil. Brasília, DF: Conselho Federal de Piscologia, 2001. p. 115-221

PESSOTTI, I. O século dos manicômios. São Paulo (SP): Ed. 34; 1996.

PICHON-RIVIERE, E. - O Processo Grupal. Martins Fontes, São Paulo, 1982.

ROSA, D. - A Compreenssão do Significado da Responsabilidade Profissional da Enfermeira. Tese de Doutorado não publicada. Programa de Pós-graduação em Enfermagem. EERP-USP, 1999.

SAMPAIO, J. J. C., SANTOS, A. W. G.; ANDRADE, L. O. M. Saúde mental e cidadania: um desafio local. In: VILAÇA, E. (Org.). A organização de saúde no nível local. Revista Saúde Loucura. São Paulo: Hucitec, p. 267-280, 1998

SILVA, M. A. A. B. M.; OLIVEIRA, E. N.; MARTINS JÚNIOR, T. Organização da nova rede de atenção mental do município de Sobral. Sanare: Revista de Políticas Públicas, Sobral-CE -, ano II, n. 3, p. 29-36, 2000.

SPINK, M. - As Representações Sociais e sua Aplicação na Área da Saúde. Cortez, São Paulo, 1989.

SPINK, M. (org.) - O Conhecimento no Cotidiano. As Representações Sociais na Perspectiva Social. Brasiliense, São Paulo, 1993.

SOUZA, R.C.; SCATENA, M.C.M. Produção de sentidos acerca da família que convive com o doente mental. Revista Latino-Americana de Enfermagem. v.13, n.2, 2005. p.173-179.

OLIVEIRA, M.B. e JORGE, M.S.B. Doente mental e sua relação com fmília In LABATE, R. C. (Org.). Caminhando para a assistência integral. Ribeirão Preto: Scala, 1998.

Como citar este artigo (Formato ABNT):

BRAGA, I.B. ; VASCONCELOS, J.F.; VIEIRA, A.C.C.; MARANHÃO, T.L.G. Representações Sociais de Doente Mental na Percepção dos Cuidadores. Id on Line Revista de Psicologia, Julho de 2015, vol.9, n.27. p. 98-117. ISSN 1981-1189.

Recebido: 06/02/2015

Aceito:19/02/2015 